References

Oppenheimer, R., Howells, K., Palmer, R. L. \& Chaloner, D. A. (1985) Adverse sexual experience in childhood and clinical eating disorders: a preliminary description. Journal of Psychiatric Research, 19, 357-361.

SCott, R. \& THONER, G. (1986) Ego deficits in anorexia nervosa patients and incest victims: an MMPI comparative analysis. Psychological Reports, 58, 839-846.

SLOANE, G. \& LeICHNER, P. (1986) Is there a relationship between sexual abuse or incest and eating disorders? Canadian Journal of Psychiatry, 31, 656-660.

\section{Compensation Psychosis}

SIR: Involvement in an accident and subsequent compensation issues can be a significant psychogenic stimulus to precipitation of an endogenous depressive psychosis, particularly in individuals with a genetic predisposition. This would seem to be so in the case described by Pilowsky \& Lee (Journal, December 1987, 151, 868-869). Such a depressive psychosis should respond to antidepressant medication and ECT (we assume there was some physical contraindication to ECT in this case). We find it difficult to accept a primary diagnosis of morbid grief reaction 'complicated' by a psychotic depression when the wife's death and the husband's involvement in litigation began fifteen months prior to the onset of the depressive psychosis. In psychopathological terms, the wife's death and the compensation issues 'colour' the psychosis and are part of the content, but they are not aetiological in nature and to label the psychosis in terms of its content is incorrect.

In the original case of so-called "compensation psychosis' (White et al, Journal, May 1987, 150, 692-694) the patient had received a head injury and sustained brain damage, albeit minimally, which was manifest in a chronic amnestic syndrome. To label this organic psychosis as a 'compensation psychosis' is again to ascribe a primary aetiology to the issues of compensation when the primary aetiology is one of brain damage. It would seem to us that the lawyers got it right when they awarded this patient substantial damages $(£ 50000)$ for the brain damage he sustained in the accident and not for compensation.

We would contend that the concept of a 'compensation psychosis' is not only nosologically incorrect and fallacious, but in medico-legal terms misleading.

G. G. HAY

Department of Psychiatry

J. JOHNSON

Withington Hospital

West Didsbury

Manchester M20 8LR
SIR: Drs Hay and Johnson correctly identify nosological and medico-legal dangers in premature acceptance of a journalistic term such as 'compensation psychosis' as a diagnosis. We share their view. This is why we called for a systematic investigation and review of such cases.

We do not agree with their formulation of the case that we reported, although we do wish that we shared their certainty. Our patient's losses and the compensation issues may have been merely precipitants and pathoplastic features of an endogenous depression. But we were also impressed by the complex interplay of grief and compensation as having a direct aetiological and maintaining role in the illness. Surely there is room here for a multifactorial aetiology?

Our main point remains. However their illnesses are categorised, these patients are a group of growing importance who have special needs and who warrant further study.

\section{LYN PILOWSKy} Alan LeE

The Maudsley Hospital

Denmark Hill

London SE5

SIR: Drs Johnson and Hay wish to reject the concept of compensation psychosis on the grounds that in the case described the syndrome arose in the setting of an organic psychosis caused by a head injury. We would agree that brain damage may well have been the underlying organic pathology, but the name 'compensation psychosis' does not imply that the compensation factor was the primary cause but rather that the nature of the delusions was influenced by an ongoing compensation case. (We would contend that in most cases of compensation neurosis it is the accident which causes the neurosis, but the condition may be aggravated by litigation proceedings). In other "uncommon psychiatric syndromes" (Enoch et al, 1967), e.g. de Clérambault syndrome and Capgras syndrome, it is the nature of the delusions which characterise these syndromes - not the cause (Sims \& White, 1973).

In the case described, the patient was awarded damages partially on account of the suffering he had endured, but particularly because it was considered that he would not be able to return to his job of work - the details of his disability hardly figured in the negotiations! Solicitors are not overly interested in syndromes.

Queen Elizabeth Medical Centre

Alfred White

Edgbaston

Birmingham B15 2TH 


\section{References}

Enoch, M. D., Trethowan, W. H. \& Barker, J. C. (1967) Some Uncommon Psychiatric Syndromes. Bristol: John Wright.

Sims, A. \& WhITE, A. (1973) Coexistence of the Capgras and de Clérambault syndromes: a case history. The British Journal of Psychiatry, 123, 635-638.

\section{Research in Psychotherapy}

SIR: The report by Shapiro \& Firth (Journal, December 1987, 151, 790-799) provides an opportunity to ponder on the requirements of psychotherapeutic research. I venture to make my criticisms in the hope that debate will lead to improvement in this field of study. I will consider some principles under the following headings: (a) specifying the therapeutic intervention; (b) defining the subjects treated; (c) consideration of assessment methods; and (d) the design of the study.

Firstly, the therapeutic techniques. Any single technique, such as anxiety management training, contains within its structure a sufficient number of potentially therapeutic interventions to keep a large number of researchers busily occupied for many years in the effort to determine which are the most important interventions. The authors quote the 'dodo-bird verdict', i.e. that all therapeutic methods have some effect; alright then, but what is now required is enquiry into the effective elements. To amalgamate a number of techniques does little to advance knowledge, since one cannot know what, among the pot pourri of strategies, was bringing about the improvement.

Secondly, the characteristics of the sample of subjects must be most carefully described if there is to be any hope of drawing useful conclusions from the study. The authors' sample consisted of patients referred by doctors and people who had referred themselves; there was some negative information i.e. that they had not suffered from psychiatric disorder for more than two years and that psychotic and obsessional symptoms were absent; all complained that their work was affected by their problems; but there description closed. Judgement of psychotherapeutic procedures has too often led to scepticism because of their practitioners' claims that all people will benefit no matter what their disorder or problem may be. Such claims of universality should be abandoned by serious researchers, who should address the specific issues of just what types of disorder are helped by exactly which therapeutic approach.

Thirdly, assessment instruments must have been shown to be valid and reliable measures in the proposed field of application. The prevalent habit, followed by the authors, of selecting instruments composed of the whole gamut of psychiatric symptomatology (in their case the PSE and the SCL) and reporting change in terms of a fall in scores is not a procedure to be endorsed: it is equivalent to studying a treatment for a cardiac disorder in terms of a measure composed of all symptoms of somatic illness and reporting the result in terms of an improvement in an unspecified number of them. The most meaningful psychotherapy outcome research involves the task of defining the goals of treatment and measuring outcome by some technique such as Goal Attainment Scaling, in terms of the proportion of subjects achieving the aim: Mulhall's Rapid Scaling Technique is another useful device, and the authors incorporated it, although they did not present their results in terms of it.

Finally, the design. Cross-over designs in comparison of treatment methods introduce unfathomable complications in the interpretation of the results. The greatest need in psychotherapy research is not the comparison of one procedure with another, but the ascertainment of the durability of improvement. This requires a long follow-up interval following the intervention. This is a stringent requirement, especially when the duration of research posts is limited, but it is one which must no longer be dodged. Psychotherapy is an expensive intervention and there are those who have argued cogently that present information concerning outcome does not justify its use in a state-funded health service. Psychotherapy researchers must now demonstrate, not that they can produce short-term improvement, but that the improvement is lasting once contact with the therapist has ended.

One more point, regarding cost-effectiveness. Future research reports should clearly state the cost of the treatment in terms of the total time of therapist intervention and the training or skill, and hence 'expense', of the therapist.

Department of Psychiatry

R. P. SNATTH

St James's University Hospital

Leeds LS9 7 TF

SIR: Dr Snaith's letter provides an opportunity to emphasise the wide-ranging and complementary research strategies that are required in the psychotherapy field. Comparative outcome studies are but one part of the overall effort to develop and identify effective and efficient treatments (Stiles et al, 1986). We will reply to each of DrSnaith's comments in turn.

(a) Therapeutic techniques. Of course any method can and should be analysed into its constituent elements, to identify the helpful components. Such 